\title{
Financial Targets for the Sponsee and the Sponsor in the Restoration/Recovery of the Historical and Architectural Heritage
}

\author{
Luigi Dolores $^{(\triangle)}(\mathbb{D}$, Maria Macchiaroli (D), and Gianluigi De Mare (D) \\ University of Salerno, Via Giovanni Paolo II, 132, Fisciano (SA), Italy \\ \{ldolores, mmacchiaroli, gdemare\}@unisa.it
}

\begin{abstract}
The paper explores the theme of sponsorship for the restoration/recovery of the historical-architectural heritage. The goal is to propose a model that allows both the sponsee (often public institution) and the sponsor company (mainly private) to maximize the monetary return generated by the investment. The model is tested through the following case study: the sponsorship of the restoration works of the Don Tullio's Fountain located in the Villa Comunale of Salerno (Italy). In the logic of the model, the funding requested by the sponsee is necessarily inclusive of the amount equal to the cost of the restoration work but should also consider the financial advantage deriving from the advertising return to the sponsor company. These targets are estimated through the direct audience critical variable connected with the number of visitors of the location of interest. For the sponsor, on the other hand, assuming a Cobb-Douglas production function, it's possible to quantify under static conditions the optimal percentage of turnover to invest in sponsorship to maximize profits. Assuming, therefore, that several companies are interested in sponsoring the restoration of the monument, the application of the model makes it possible to determine which company would be most suitable to sign the sponsorship contract.
\end{abstract}

Keywords: Sponsorship $\cdot$ Advertising fees $\cdot$ Cultural heritage $\cdot$ Profitability of investment $\cdot$ Public-private partnership

\section{Introduction}

Local development understood as a process of valorisation of existing territorial resources is based on the dialectic interaction between endogenous and exogenous processes. Therefore, it's synonymous with mutual influence between the local and external dimensions. In this perspective, the challenge is to increase the value of the identity capital (natural, physical, human, social and symbolic) of a territory [1]. Among the identity resources that characterize local realities, cultural heritage plays a primary role. Policies to promote local development often include among their main goals that of improving the enjoyment of the historical-artistic heritage. This often happens through

\footnotetext{
L. Dolores, M. Macchiaroli and G. De Mare — Contributed equally to this work.

(C) The Author(s) 2020

C. Bevilacqua et al. (Eds.): NMP 2020, SIST 177, pp. 155-165, 2020.

https://doi.org/10.1007/978-3-030-52869-0_13
} 
the elaboration of management models based on multi-level planning focused on forms of partnership between institutions and companies of the territory [2-7].

Among the main forms of public-private partnership, sponsorship represents a valid instrument for the enhancement of cultural heritage that offers several advantages to both public administrations and companies. The latter, taking on the role of sponsors, use cultural sponsorship to strengthen or rebuild their corporate image and corporate reputation as well as to achieve a variety of objectives: improving relations with customers, fostering relations with bodies and institutions, improving relations with suppliers, and generating consensus in society. Another important advantage is the monetary return generated by the investment in sponsorship. On the other hand, public bodies, taking on the role of sponsees, not only obtain from companies the financial or in-kind means necessary to organise and carry out a given activity but by interacting with the business world they contribute to the social and economic development of the territory [8].

The objective of the work consists in proposing and testing through a case study, set in the city of Salerno (Italy), a model that allows the sponsor to maximize the profits generated by the investment in sponsorship and, at the same time, the sponsee to optimize the amount of funding obtained by the company. The financing companies can thus establish the optimum percentage of turnover to be invested in sponsorships capable of generating the highest achievable profit. For Public Administrations, on the other hand, the model makes it possible to determine the financial resources deemed optimal to proceed with the signing of the sponsorship contract. These resources are considered to include not only the amount needed to carry out the restoration work but also an aliquot linked to the profit of the private lender and representative of the value that the candidate company intends to acquire with its offer.

\section{Methods}

The logical path of the proposed model can be divided into two phases. The problem of maximizing the economic return due to public administrations is addressed in the phase of estimating sponsorship fees [9], which is inspired by the Technical Regulations on cultural sponsorship [10]. These rules assume that the total cost of the sponsorship is established on the basis of the value of the work, services or supplies necessary for the restoration, plus an additional aliquot proportional to the value of the advertising return, expressed in both monetary and image terms, which the administration is able to offer the sponsor [11]. The mark-up, representative of the countervalue offered, is to be properly estimated based on the considered desirability of the sponsorship on the market. This allows the Administrations both to avoid, in case of overestimation, a total lack of interest on the part of the companies, and to avoid, in case of underestimation, the attribution to the private individual of services of too high a value compared to the consideration obtained. However, the monetary and image returns due to the company are in practice rarely estimated because of their difficult measurement [12]. It follows that Administrations are unlikely to maximise public return from the application of the 
instrument. To overcome the problem, when estimating the sponsorship fees, it's assumed that the advertising return offered to the sponsor is a function of various parameters, some referring to the property to be enhanced (name of the designer, time of construction, architectural quality, relevance of the property to the community) and others characterizing the sponsorship activity (media coverage, direct audience) [13]. In addition, the analysis of numerous cases of cultural sponsorship shows that the critical variable that most influences advertising fees is the direct audience, i.e. the number of visitors to the monumental locations affected by the restoration/recovery projects. The contribution of the other parameters is therefore in most cases negligible. A comparison of the examples analysed shows an almost linear relationship between unit fees and number of visitors. So, having estimated the direct audience for the location of interest and made a comparison with similar sponsorship cases, it's possible to establish a fee representative of the advertising cost with linear proportion.

The problem of maximising the business profits generated by sponsorship is addressed in the static analysis phase of the investment [14]. The latter consists in the re-elaboration of a model proposed by Bucci, Castellani and Figini [15], in which sponsorship is considered as that immaterial production factor that enters in each moment in time (static hypothesis) in the production function of the company. The model assumes a Cobb-Douglas production function [16]. Below is adopted the version proposed by Romer [17] used to explain the endogenous growth of production systems generated by human capital. In the present case, this input is replaced by the stock of sponsorships $(S)$ accumulated by the company. Knowing the revenues $(R)$ of the enterprise and the capital $(K)$, labour $(L)$ and sponsorship $(S)$, the function is defined as follows:

$$
R=K^{\alpha} L^{1-\alpha} S^{1-\alpha}
$$

Equation (1) shows constant returns to scale compared to $K$ and $L$. However, when all three factors of production are considered, it shows increasing returns to scale. We also assume for the three factors considered individually decreasing marginal returns, being $\alpha<1[18,19]$. The price of the good offered by the company is normalised to 1 . This makes it possible to relate revenues directly to the factors of production. The total profit is represented by the following formula:

$$
\pi=K^{\alpha} L^{1-\alpha} S^{1-\alpha}-r K-w L-s S
$$

where $r K$ is the cost of capital, $w L$ represents the cost of labour and $s S$ identifies the cost of sponsorship. In addition, $r, w$ and $s$ represent the unit cost of $K, L$ and $S$ respectively. The unit cost of the sponsorship $s$ is the link between the two phases. This parameter represents the cost of a single sponsorship and includes both the cost of restoration work and the cost of advertising. Therefore, estimated $s$ in the phase of estimating sponsorship fees, this value is then reintroduced in the static analysis phase 
in the following formula obtained by deriving the (2) with respect to $S$ and placing $\pi$ equal to zero:

$$
S^{*}=\left(s /(1-\alpha) K^{\alpha} L^{1-\alpha}\right)^{1-\alpha}
$$

$S^{*}$ is the number of optimal sponsorships to be financed to maximize profit. Multiplying $S^{*}$ by the unit cost of sponsorship s gives you the optimal amount to invest in sponsorship. Figure 1 shows the model's logic.

ANALYSIS FOR THE SPONSEE

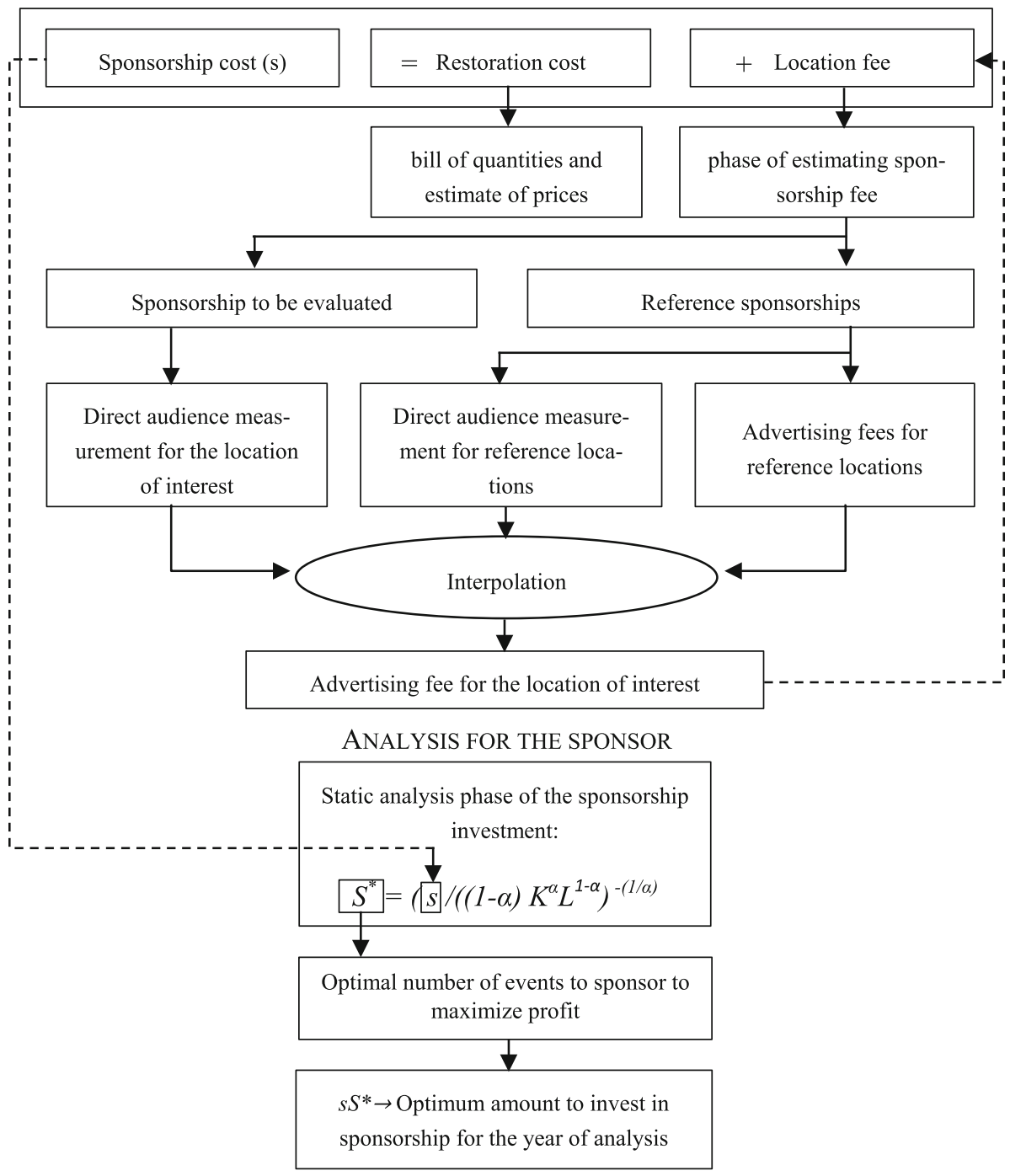

Fig. 1. Flow chart of the logical steps of the proposed model (own processing) 
In the next paragraph the model is applied to the case study. Specifically, we respond to the need of the Municipality of Salerno (Italy) to find companies willing to sponsor the restoration of the Don Tullio Fountain's located in the Villa Comunale. Furthermore, it is assumed that two companies from Campania are interested in financing the initiative. The goal is to assess which of the two is best suited to sponsor the restoration. The sponsee can consciously take advantage of this information to optimise the contractualization phase of the agreement.

\section{Application and Results}

Below is the main information about the monument and its location.

\subsection{The Monument and Location}

Don Tullio's Fountain (see Fig. 2), located in the Villa Comunale, is one of the most characteristic fountains of ancient Salerno. It currently has a medium level of degradation caused by atmospheric agents and human action.
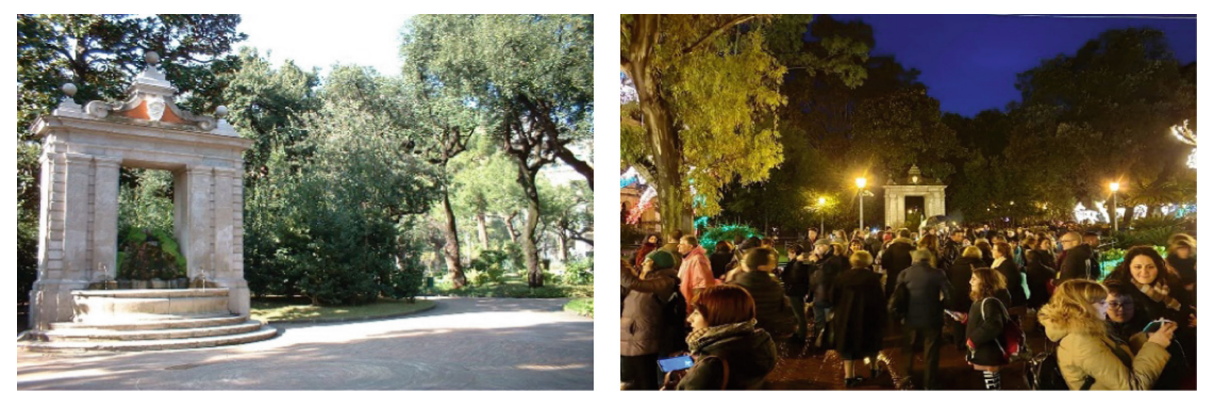

Fig. 2. Don Tullio's Fountain (own elaboration) and the Villa Comunale of Salerno during the Luci D'Artista event (source: Salerno Today, http://www.salernotoday.it).

The attractiveness for the sponsors of the location is very high. In fact, the Villa Comunale attracts many visitors during the winter period thanks to the Luci D'Artista event, which includes the installation of Christmas lights with a high scenographic value. For this reason, it's consistent to coincide the promotion phase of the company with the period (about three months) of the event. In addition, the sponsor is required to transmit its advertising message through the illuminations installed in the Villa Comunale. It's therefore a question of forcing the sponsor to integrate itself into the virtuous artistic process of the event, without losing effectiveness in the proposition of its brand. This allows both the company and the municipal administration to obtain various advantages. First, greater visibility for the sponsor is guaranteed. Secondly, a greater return on image for the company can also be an advantage for the Administration, since the latter is motivated to increase the advertising fee. Finally, avoiding the 
direct posting of billboards on scaffolding, a sponsorship method that respects the decorum and cultural value of the monument is preferred.

\subsection{The Estimate of Sponsorship Fee}

To estimate the advertising fee of the Villa Comunale, it was necessary to quantify the number of visitors to the location. The measurement of the direct audience was carried out during the last edition of Luci D'Artista in five days a week (Monday, Tuesday, Friday, Saturday and Sunday) and in two different time slots (morning and afternoonevening). The results were then extended to the whole day. It has also been assumed that the number of visitors on Wednesday and Thursday is equal to the average number of visitors on Monday and Tuesday. The average number of visitors from Monday to Thursday (low turnout days), the average number of visitors on Friday (average turnout day) and the average number of visitors from Saturday to Sunday (high turnout days) were therefore estimated. Finally, the average number of visitors per month has been estimated.

The pedestrian flows were recorded following video recordings made for each day and time slot in the location of interest. The camera has been positioned to frame all the access roads to the Villa.

In order to estimate the advertising fee of the Villa Comunale di Salerno it's necessary to make a comparison with other territorial realities in which restoration works have been sponsored. In the case in question, two locations in Naples were selected for comparison, in each of which there is a monument that has been sponsored. The monuments chosen are the Temple of Virgil, whose location is the Villa Comunale, and the Via Chiaia Bridge located in the street of the same name. For the two locations in Naples, pedestrian flows were recorded in the same way as for Salerno. Table 1 shows the estimated visitor numbers for the locations in both cities.

Table 1. Average visitors for the locations of Naples and Salerno (source: own processing)

\begin{tabular}{l|l|l|l|l|l|l}
\hline City & \multicolumn{3}{l}{ Salerno } & \multicolumn{2}{l}{ Naples } \\
\hline Location & Villa Comunale & \multicolumn{2}{l}{ Via Chiaia } & \multicolumn{2}{l}{ Villa Comunale } \\
\hline \multirow{2}{*}{ Morning (10:30-14:30) } & Mon-Thu & 812 & Mon-Thu & 712 & Mon-Thu & 483 \\
\cline { 2 - 7 } & Fri & 2,930 & Fri & 10,740 & Fri & 760 \\
\cline { 2 - 7 } & Sat-Sun & 5,765 & Sat-Sun & 26,465 & Sat-Sun & 2,115 \\
\hline \multirow{2}{*}{ Afternoon-evening (15:00-19:00) } & Mon-Thu & 4,540 & Mon-Thu & 3,870 & Mon-Thu & 315 \\
\cline { 2 - 7 } & Fri & 14,215 & Fri & 9,675 & Fri & 538 \\
\cline { 2 - 7 } & Sat-Sun & 27,835 & Sat-Sun & 19,530 & Sat-Sun & 1,620 \\
\hline Average daily visitors & Mon-Thu & 5,352 & Mon-Thu & 4,582 & Mon-Thu & 798 \\
\cline { 2 - 7 } & Fri & 17,145 & Fri & 20,415 & Fri & 1,298 \\
\cline { 2 - 7 } & Sat-Sun & 33,600 & Sat-Sun & 45,995 & Sat-Sun & 3,735 \\
\hline Average monthly visitors & 288,612 & & 338,952 & & 32,900 & \\
\hline
\end{tabular}


Table 2 shows the fees of the locations in Naples extrapolated from the technical sheets drawn up and disseminated by the Municipal Technical Office.

Following an inspection of the Villa Comunale in Salerno, carried out during the last edition of Luci D'Artista, it was possible to quantify the square meters of lights convertible into exhibition space for the sponsor. Specifically, it's estimated that the total area of the lighting installations is about $1,000 \mathrm{~m}^{2}$.

Table 2. Data related to the sponsorship for the restoration of the monuments of Naples

\begin{tabular}{l|l|l}
\hline Location & Via Chiaia & Villa Comunale \\
\hline Monument & Via Chiaia Bridge & Temple of Virgil \\
\hline Exhibition area $\left[\mathrm{m}^{2}\right]$ & 150 & 190 \\
\hline Exposure period [months] & 8 & 4 \\
\hline Cost of sponsorship $[€]$ & 260,000 & 80,000 \\
\hline Cost of restoration work $[€]$ & 210,000 & 63,000 \\
\hline Advertising cost $[€]$ & 50,000 & 17,000 \\
\hline Unit cost of advertising $\left(€ /\left(\mathrm{m}^{2} \times\right.\right.$ month $\left.)\right)$ & 42 & 22 \\
\hline Resale price $[€ /$ month] & 120,000 & 80,000 \\
\hline Unit resale price $\left(€ /\left(\mathrm{m}^{2} \times\right.\right.$ month $\left.)\right)$ & 800 & 421 \\
\hline
\end{tabular}

The fee (unit cost of advertising) for the Salerno location, deduced in linear proportion to the number of monthly visitors, is shown in Table 3.

The cost of the restoration work on the Don Tullio's Fountain was estimated through the elaboration of an estimated metric calculation. The total cost of the sponsorship $s$ is equal to the sum of the cost of the restoration work and the cost of advertising, as reported in Table 4.

Table 3. Unit and total advertising cost for the Villa Comunale di Salerno

\begin{tabular}{l|l|l|l|l|l}
\hline Location & $\begin{array}{l}\text { Exposure } \\
\text { period } \\
{[\text { months }]}\end{array}$ & $\begin{array}{l}\text { Exhibition } \\
\text { area }\left[\mathrm{m}^{2}\right]\end{array}$ & $\begin{array}{l}\text { Unit cost of } \\
\text { advertising }[(€ / \\
\left.\left(\mathrm{m}^{2} \times \text { month }\right)\right] .\end{array}$ & $\begin{array}{l}\text { Total cost } \\
\text { of } \\
\text { advertising } \\
{[€]}\end{array}$ & $\begin{array}{l}\text { Total cost of } \\
\text { rounded } \\
\text { advertising } \\
{[€] .}\end{array}$ \\
\hline $\begin{array}{l}\text { Villa } \\
\text { Comunale }\end{array}$ & 3 & 1,000 & 39 & 117,000 & 120,000 \\
\hline
\end{tabular}

The total cost of sponsorship $s$ is used as a key figure in the second phase of the model, in which it is intended to estimate the optimal budget that the companies concerned should invest in sponsorship. 
Table 4. Advertising costs, costs for the restoration works and total costs of the sponsorship activity for Don Tullio's Fountain

\begin{tabular}{l|l|l|l}
\hline Monument & $\begin{array}{l}\text { Advertising cost } \\
{[€]}\end{array}$ & $\begin{array}{l}\text { Cost of restoration } \\
{[€]}\end{array}$ & $\begin{array}{l}\text { Total cost of sponsorship } \\
s[€]\end{array}$ \\
\hline $\begin{array}{l}\text { Don Tullio's } \\
\text { Fountain }\end{array}$ & 120,000 & 60,000 & 180,000 \\
\hline
\end{tabular}

\subsection{The Optimal Investment Estimate for Companies}

At this stage it's assumed that two companies from Campania (Company A and Company B) are interested in sponsoring the restoration work on the Don Tullio's Fountain. Company A is active in the production and distribution of food products, while Company B is active in the clothing sector. The selected companies have already gained some experience in the field of cultural sponsorship. Table 5 shows the economic data needed to solve the optimization problem, extrapolated from the latest financial statements (closing date 31/12/2018) published by both companies. Company A did not invest in sponsorship in the year under review. Assuming therefore that it accepts the sponsorship proposal of the Municipality of Salerno we can put $S=1$ and $s S=€ 180,000$. Differently, Enterprise B in the year of analysis has already invested $€$ 12,000 in sponsorships, that is about $7 \%$ of the amount requested by the Municipality of Salerno. If you also accept the proposal of the Municipal Administration, we can put $S=1.07$ and $s S=€ 192,000$.

Table 5. Financial statement data at $31 / 12 / 2018$ for the two companies under analysis

\begin{tabular}{l|l|l|l}
\hline Type of data & Symbology & Company A & Company B \\
\hline Production value & $\mathrm{R}$ & $€ 14,712,120$ & $€ 153,166,000$ \\
\hline Cost of production (including sS) & $\mathrm{C}_{\mathrm{T}}$ & $€ 13,749,998$ & $€ 164,127,560$ \\
\hline Earnings before interests and taxes (EBIT) & $\pi$ & $€ 962,122$ & $-€ 10,961,560$ \\
\hline Cost of capital (excluding sS) & $\mathrm{rK}$ & $€ 12,018,866$ & $€ 136,684,846$ \\
\hline Labour costs & $\mathrm{wL}$ & $€ 1,551,132$ & $€ 27,250,714$ \\
\hline Cost of sponsorship & $\mathrm{sS}$ & $€ 180,000$ & $€ 192,000$ \\
\hline Capital & $\mathrm{K}$ & $€ 19,911,907$ & $€ 167,727,663$ \\
\hline Labour & $\mathrm{L}$ & 42 & 1,068 \\
\hline Sponsorships & $\mathrm{S}$ & 1.00 & 1.07 \\
\hline Unit cost of capital & $\mathrm{r}$ & 0.6 & 0.82 \\
\hline Unit labour cost & $\mathrm{w}$ & $€ 36,932$ & $€ 25,515.65$ \\
\hline Sponsorship unit cost & $\mathrm{s}$ & $€ 180,000$ & $€ 180,000$ \\
\hline & & &
\end{tabular}


The log-linearity property of the Cobb-Douglas function allows to estimate the marginal productivity constant $\alpha$, with the following formula:

$$
\ln R=\alpha \ln k+(1-\alpha) \ln L+(1-\alpha) \ln S .
$$

From (4) for Enterprise A you get:

$$
\alpha_{A}=\left(\ln R_{A}-\ln L_{A}-\ln S_{A}\right) /\left(\ln K_{A}-\ln L_{A}-\ln S_{A}\right)=0.977
$$

Also, from (4), for enterprise B we have:

$$
\alpha_{B}=\left(\ln R_{B}-\ln L_{B}-\ln S_{B}\right) /\left(\ln K_{B}-\ln L_{B}-\ln S_{B}\right)=0.992
$$

From the application of (3) for Company A we obtain $S_{A^{*}}=1.92$. Therefore, for this company the optimal amount to invest to maximize profit is $s S_{A} *=€ 345,884.98$ (about $2.4 \%$ of turnover). By placing in (2) $S={ }_{S A} *$ we obtain the maximum possible profit for Company A, equal to $\pi_{M A X, A}=€ 1,020,451.68$.

On the other hand, applying (3) to Enterprise B results in $S_{B} *=6.59$. So, in this case the optimal amount to invest to maximize profit is $s S_{B} *=€ 1,185,319.29$ (about $0.8 \%$ of turnover). By placing in (2) $S=S_{B} *$ we obtain the maximum possible profit for Company $\mathrm{B}$, equal to $\pi_{M A X, A}=-€ 9,812,193.61$.

\section{Conclusions}

In Italy, sponsorship of cultural heritage represents one of the main forms of interaction between public and private with which it's possible to guarantee an efficient valorisation of the historical-architectural heritage [20].

The work aims to propose a model for estimating the profitability of sponsorship that is useful for both the sponsee and the sponsor. The implementation of the model in the case study made it possible to quantify the right amount due to the Municipal Administration, including not only the sums needed for the interventions but also the advertising return granted by the public body to the company. At the same time, for two companies in Campania, which are supposed to be interested in financing the restoration work, the optimal investment in sponsorship capable of maximizing entrepreneurial profit was estimated.

The application shows that for the first company, not only is the investment in sponsorship convenient, but its efficiency is maximised when the financing is doubled. In this case, a profit surplus of $€ 58,329.68$ is generated, i.e. an increase of $6 \%$. For this company, it's advisable to accept the sponsorship proposal of the municipal administration together with another possible offer structurally like the first one both in terms of characteristics and financial weight.

For the second company, which closed the year at a loss, sponsorship would seem to be uneconomic. Maximising profits requires a financial effort six times greater than that required by the municipal administration. Also, in the excellent condition, the profits remain negative. However, operating losses decrease by about $€ 1.15$ million, or 
almost $10 \%$. It would, therefore, be interesting for this company to analyse the effects of sponsorship in the long term (dynamic analysis), to see whether the investment made today contributes to a positive return in subsequent years.

The model analyses the profitability of sponsorship from both the sponsor and the sponsee's point of view, allowing for the alignment of their objectives. However, it has several limitations, due to the simplifying hypotheses adopted. To overcome them, in future research, greater importance will be given to the other parameters that influence sponsorship fees and a more complex production function will be adopted.

\section{References}

1. Nesticò, A., Maselli, G.: Sustainability indicators for the economic evaluation of tourism investments on islands. J. Clean. Prod. 248, 119217 (2020). https://doi.org/10.1016/j.jclepro. 2019.119217

2. Seravalli, G.: Innovazione e sviluppo locale - Concetti, esperienze, politiche. Economia E Politica Industriale 1, 75-106 (2008)

3. Nesticò, A., De Mare, G., Fiore, P., Pipolo, O.: A model for the economic evaluation of energetic requalification projects in buildings. a real case application. In: Murgante, B., et al. (eds.) ICCSA 2014. LNCS, vol. 8580, pp. 563-578. Springer, Cham (2014). https://doi.org/ 10.1007/978-3-319-09129-7_41

4. Nesticò, A., Macchiaroli, M., Pipolo, O.: Historic buildings and energetic requalification a model for the selection of technologically advanced interventions. In: Gervasi, O., et al. (eds.) ICCSA 2015. LNCS, vol. 9157, pp. 61-76. Springer, Cham (2015). https://doi.org/10. 1007/978-3-319-21470-2_5

5. Nesticò, A., He, S., De Mare, G., Benintendi, R., Maselli, G.: The ALARP principle in the cost-benefit analysis for the acceptability of investment risk. Sustainability 10(12), 4668 (2018). https://doi.org/10.3390/su10124668

6. De Mare, G., Nesticò, A., Macchiaroli, M.: Significant appraisal issues in value estimate of quarries for the public expropriation [Questioni estimative di rilievo nella stima del valore di cave per l'espropriazione]. Valori e Valutazioni 18, 17-23 (2017). ISSN: 2036-2404

7. Macchiaroli, M., Pellecchia, V., D'Alpaos, C.: Urban water management in Italy: an innovative model for the selection of water service infrastructures. WSEAS Trans. Environ. Develop. 15, 463-477 (2019). Print ISSN: 1790-5079. E-ISSN: 2224-3496. doi: a985115071

8. Tocci, M.: Lineamenti sul contratto di sponsorizzazione dei beni culturali. Filodiritto Editore, Bologna (2015)

9. Dolores, L., Macchiaroli, M., De Mare, G.: A model for defining sponsorship fees in publicprivate bargaining for the rehabilitation of historical-architectural heritage. In: Calabrò, F., Della Spina, L., Bevilacqua, C. (eds.) ISHT 2018. SIST, vol. 101, pp. 484-492. Springer, Cham (2019). https://doi.org/10.1007/978-3-319-92102-0_51

10. Di Mauro, F.: Le norme tecniche e linee guida applicative delle disposizioni in materia di sponsorizzazioni di beni culturali: i tratti essenziali. Aedon, Rivista di arti e diritto online. Il Mulino - Rivisteweb 3 (2012)

11. Rossi, F.: Sponsorizzazione sportiva e relazioni pubbliche: analisi di uno strumento di comunicazione integrata. Nuove proposte per il mondo professionistico. Master's degree Thesis, University of Padua, Department of linguistic, Padua, Italy (2016)

12. Pham, M.T.: The evaluation of sponsorship effectiveness: a model and some methodological considerations. Gestion 2000, 47-65 (1991) 
13. Cornwell, T.B., Maignan, I.: An international review of sponsorship research. J. Advert. 27 (1), 1-21 (1998)

14. Dolores, L., Macchiaroli, M., De Mare, G.: Sponsorship for the sustainability of historicalarchitectural heritage: application of a model's original test finalized to maximize the profitability of private investors. Sustainability 9(10), 1750 (2017). https://doi.org/10.3390/ su9101750

15. Bucci, A., Castellani, M., Figini, P.: L'investimento in Sponsorizzazione delle Imprese: Un'analisi Economica in Termini Statici e Dinamici. Rivista di Politica Economica 93, 183$224(2003)$

16. Cobb, C.W., Douglas, P.H.: A theory of production. Am. Econ. Rev. 18, 139-165 (1928). https://www.jstor.org/stable/1811556

17. Romer, P.M.: Increasing returns and long run growth. J. Polit. Econ. 94(5), 1002-1037 (1986)

18. Solow, R.M.: Lezioni sulla Teoria della Crescita Endogena. Carocci, Rome (1994)

19. Ardeni, P.G.: Teorie della Crescita Endogena. Giappichelli, Torino (1995)

20. Dolores, L., Macchiaroli, M., De Mare, G.: A dynamic model for the financial sustainability of the restoration sponsorship. Sustainability 12(4), 1694 (2020). https://doi.org/10.3390/ su12041694

Open Access This chapter is licensed under the terms of the Creative Commons Attribution 4.0 International License (http://creativecommons.org/licenses/by/4.0/), which permits use, sharing, adaptation, distribution and reproduction in any medium or format, as long as you give appropriate credit to the original author(s) and the source, provide a link to the Creative Commons license and indicate if changes were made.

The images or other third party material in this chapter are included in the chapter's Creative Commons license, unless indicated otherwise in a credit line to the material. If material is not included in the chapter's Creative Commons license and your intended use is not permitted by statutory regulation or exceeds the permitted use, you will need to obtain permission directly from the copyright holder.

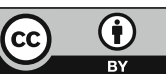

